\title{
Stomach Content Analysis of Feed and Feeding Habit of Oreochromis Niloticus Fish Species in Baro-Akobo Basin, South West Ethiopia in Case of Alwero Dam
}

\author{
Keredin Mohamed Habib Ashenafi Assefa Adunga \\ Department of Animal Production and Technology, College of Agriculture and Natural Resources, Gambella \\ University, P. O. Box 126, Gambella, Ethiopia
}

\begin{abstract}
The food and feeding habit of Oreochromis niloticus inhabiting Alwero dam water body was investigated. This study was carried out to identify the type and availability of food consumed by fish. Two hundred fifty fish were obtained from the reservoir during wet and dry season. Total length (TL; cm) and Total weight (TW; g) of each fish was measured. The fish body was dissected and the entire gut was removed. The stomachs were opened and its content was poured on a petridish and stirred with water drops. The food materials were identified visually and using microscope. The fish sizes ranged between 26.5 to $39 \mathrm{~cm}$ (TL) and $390-1400 \mathrm{~g}$ (TW). More than quarters of the fish caught in Alwero dam have (80.4\%) full and (19.6\%) empty stomach. The study reveals the importance of zooplankton (34\%), fish remain (27), phytoplankton (22\%), insect part and mud /sand ( $8 \%$ ) form important items in the diet of this species. Size based differences were showed highly significance by shifting of their feeding behavior from eating zooplankton to phytoplankton as size increased and seasonal availability was additional factor for ontogenetic shift. Morphometric relationship of total weight and total length were showed a linear relationship indicating effect of length over weight and vice versa.
\end{abstract}

Keywords: Nile tilapia, Oreochromis niloticus, food and feeding, zooplankton, Alwero dam.

DOI: $10.7176 / \mathrm{JBAH} / 11-3-01$

Publication date: February $28^{\text {th }} 2021$

\section{Introduction}

Ethiopia is rich in water resources including ponds, lakes, rivers, reservoirs and wetlands. These water bodies are home for more than 150 fish species that have a great ecological and economic importance (Abebe Getahun, 2007). Oreochromis niloticus is a popular species among bony fishes in Africa including Ethiopia which is one of the most important cichlids for commercial and subsistence fisheries and it contributes about $60 \%$ of total landing in Ethiopia (LFDP, 1997).

Oreochromis niloticus is one of the most preferred species for consumption, and important for income generation in commercial as well as traditional fishermen in the country (Alemayehu Negassa and Prabu, 2008). This species has been introduced in many parts of the world such as Asia, Europe, North America and South America (Mark et al., 2005; Alemayehu Negassa and Prabu, 2008). The species has great significance in commercial fisheries in many African water bodies, and in aquaculture worldwide. This happens due to its fast growth rate, ability to reproduce in artificial conditions, high salinity tolerance, ability to survive in low dissolved oxygen concentrations, and in poor water quality, and has a wide range of feeding habits favoring to produce large quantities in a small area within a short period of time (Alemayehu Negassa and Prabu, 2008).

A study of the primary diet of Oreochromis niloticus has been inconsistent in much of the research papers. Some studies classified O. niloticus as omnivorous and others as herbivorous (Canonico GC, et.,al 2005). There is a good deal of information on the food and feeding habits of O. niloticus in many water bodies (Lubaba, 2017)

Analysis of feeding dynamics in fishes is essential prerequisite for the rational and sustainable management of the fish stocks. The spatial and seasonal fluctuations in abundance of the organisms that constitute the food of a species have been found to affect and influence biological activities of fishes such as growth, condition, shoaling behavior, migration, and the fishery. In ecosystem based fishery management studies, these data are integrated into conceptual models that allow a better understanding of the structure and function of diverse aquatic ecosystems.

Information on the gut contents of the marine fishes is necessary to understand community ecology, structure and stability of food webs, trophodynamics, resource partitioning, and functional role of different fishes in aquatic ecosystems and ecological energetics. It has been pointed out that there was a correlation between the availability of a preferred food item of a particular fish species and occurrence and abundance of the fishery for the species. Thus the study of the food of a fish around the year is essential for a better understanding of the biology and fishery of the species.

Agricultural expansion has led to an extensive ecological degradation of water bodies and making them no longer sustainable in providing goods and services due to degradation and depletion has the most immediate impact on rural poverty, food insecurity, malnutrition and under-nutrition are closely linked to the degradation of 
environment. The study areas also share those problems due to large scale agricultural investment.

Due to the inability of capture fishery to meet the demand of the increasing population is so important to establish the aquaculture. So that aquaculture development depends on feeding of fishes. As a result, food and feeding habits of fish in their habitat should be studied. Due to it form bases for good aquaculture management system.

Feed diet analysis is useful tool aiding the implementation of an ecosystem approach to fisheries. Fish diets and feeding habits also provides the basis for understanding trophic interactions in aquatic food webs. Diets of fishes represent an integration of many important ecological components. So that examining feed and feeding habit of tilapia very important as management tool. Here, an attempt is made to fill the lacuna; therefore, this study aims at contributing to the above effort by providing critical biological and ecological information needed to guide the sustainable utilization of the fisheries resources.

\section{MATERIALS AND METHODS}

\subsection{Description of the Study Area}

The study will be conduct in Abobo district of Anuak zone of Gambella people's regional state. The site was located $807 \mathrm{~km}$ from Addis Ababa towards west (7 $51^{\prime}$ North and 3432' East), at Abobo Woreda of Gambella region. Annual mean minimum and maximum temperatures are $25{ }^{\circ} \mathrm{C}$ and $42{ }^{\circ} \mathrm{C}$, respectively, which are in the range suitable for rice crop and local people livelihoods depend on fishing from Alwero dam. The rainy season extends from April to October and the dry season lasts from November to March. Mean annual rainfall of the area varies from 800 to $1500 \mathrm{~mm}$ with a long-term average of $1400 \mathrm{~mm}$. The site is located at an altitude of 580 m.a.s. Most of the soils of the region are fluvisoil (alluvial soil type) with a $\mathrm{pH}$ of 6.1 , which is slightly acidic (Wikipedia).

\subsection{Apparatus and reagents}

Gill nets, gear, scissors, sharp knives, mat, bowl, meter rule, dissecting kits, absorbable cotton wool, hand towels, safety and protection wears, microscope and large mouth screw cap containers $4 \%$ formalin solution, $75 \%$ alcohol solution, hypochlorite solution, dusting powder, detergent, soap and tap water

\subsection{Sampling and measurement}

Samples is collecting both in dry season (February -April) and wet season (first July to - end of September). Samples of tilapia are catch using gillnets and gear. The gillnets are set overnight at sites. Two sites are sampling to increase sample size and fish length range in the sample. Fishermen's catch is also sampling for the same purpose.

Immediately after sampling, total length (TL, nearest $0.1 \mathrm{~cm}$ ) of each specimen is measure and the stomach is remove. Mean weight of stomach contents has been calculating from the occurrence of empty stomach is record whereas stomachs containing food will dissect and the contents will preserve in formaldehyde solution.

Where:

$$
n=\frac{\left(t^{2}\right)\left(s^{2}\right)}{[(a)(x)]^{2}}
$$

$\mathrm{n}=$ sample size required

$\mathrm{t}=\mathrm{t}$ value from a $\mathrm{t}$-table at $\mathrm{n}-1$ degrees of freedom for a desired sample size (1.96 for $95 \%$ confidence)

$\mathrm{s} 2=$ variance

$\mathrm{x}=$ mean CPUE

$\mathrm{a}=$ precision desired in describing the mean expressed as a proportion

Where, $\mathrm{n}$ is the sample size and $\mathrm{xi}$ are the individual fish measures.

\subsection{Stomach content analysis:}

In the laboratory, the benches were cleaned and disinfected with hypochlorite solution. The specimen containers were brought and laid down on to the cleaned and disinfected benches. The content of each stomach was transferred into a Petri-dish to identify food items visually and/or microscopically. Large food items, particularly fish, are identified visually. However, the sample is examined under a microscope for smaller food items which were identified to the lowest taxa possible using descriptions in the literature (Mamaril and Fernando, 1978 Pennak, 1978; Edington and Hildrew, 1981; Defaye, 1988). Simultaneously with identification, food items were counted to estimate their numerical contribution to the diet of the fish

The gut contents would be analyzed using frequency of occurrence and numeric methods based on (Hynes 1950). In the frequency of occurrence method, the occurrence of food items was expressed as the percentage of the total number of stomach containing food, while in the numeric method each individual of food type in stomach was counted and expressed as a percentage of the total number of food items in the sample studied, or 
as a percentage of the gut contents of each specimen examined from which the total percentage composition is estimated.

Where, $\mathrm{N}_{\mathrm{i}}$ is the number of food category $\mathrm{i}$

$$
\text { Percent by number, } \mathrm{N}_{\mathrm{i}}=\frac{\mathrm{N}_{\mathrm{i}}}{\sum_{\mathrm{i} 1}^{\mathrm{Q}} \mathrm{N}_{\mathrm{i}}}
$$

Estimation of Relative Importance of Food Items

The relative importance of food items to the diet of Oreochromis niloticus would analyzed using the frequency of occurrence and the numerical abundance methods (Windell and Bowen, 1978; Hyslop, 1980). Results from those methods served as bases to identify major and minor food items based on number and weight of individuals in catches as well as their frequency of occurrence

\subsection{Investigation of Size-based and Seasonal Differences in Food Habit}

Size-based difference in food habit of the fish was studied by plotting frequency of occurrence of major food items against TL (total length) of the fish. 'Seasonal differences in the food habit is study by plotting the relative importance (frequency of occurrence and numerical abundance) of major food items as well as the frequency of fish with empty stomachs against sampling season

\subsection{Data Analysis}

Data obtain are subject to simple statistical tools of analysis by using percentage, mean and standard deviation in order to ascertained the significance of the variables obtained. SPSS version 20 and Microsoft Excel sheet would be used to analyze and managed the data

\section{RESULTS AND DISCUSSION}

\subsection{Morphometric relationship}

A total of 250 fish samples from 26 to $39.2 \mathrm{~cm}$ in TL and 0.390 to $1400 \mathrm{~g}$ in TW were used to determine length weight relationships. The relationship between TL and TW was linear and significant $(\mathrm{p}<0.001)$ (fig.5)

O. niloticus fish were collected from Alwero dam were measured from $26 \mathrm{~cm}$ to $39 \mathrm{~cm}$ of total length of height. Nearly $80 \%$ of captured fish belong between $(32-34 \mathrm{~cm})$ ranges of total length. The large size of fishes maybe implied underutilization of dam due to fishermen shifting to the Agricultural practices during the season. This finding was relative to (Alemken Barihun and Selemon Thomas, 2020)

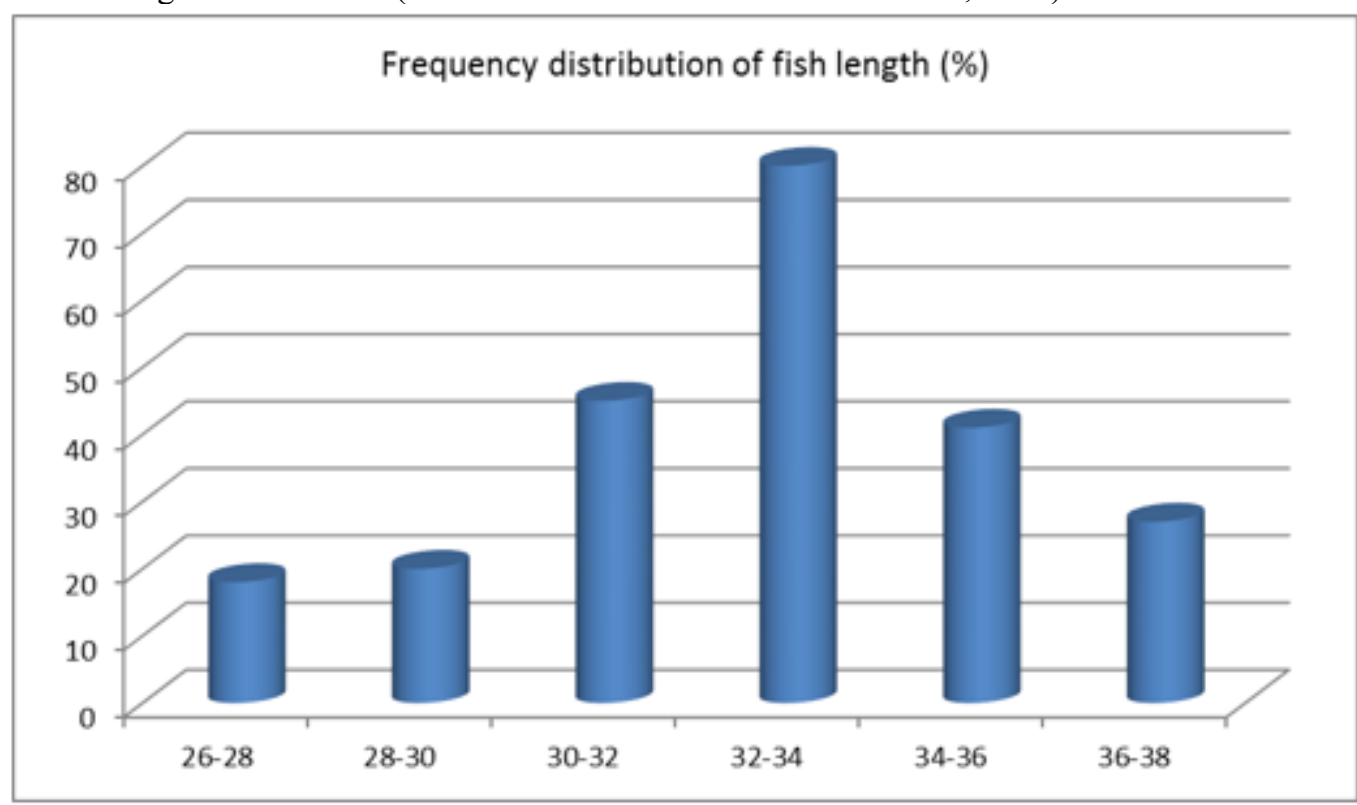

Size class in $(\mathrm{cm})$

Figure1. Length distribution of O. niloticus fish

\subsection{Composition of stomach contents}

Item identified from the stomach contents of $O$. niloticus are listed in (Table 1) for O. niloticus fish from Alwero 
dam. O. niloticus from this dam had ingested diverse groups of organisms of both plant and animal origins and muds. In both populations, items of plant origin ingested by the fish were phytoplankton. Item of animal origin ingested by $O$. niloticus were zooplankton, insect, nematodes and some unidentified animals. According to Otieno etal. (2014), fish mainly feed on food items that can fit into their mouth and what their stomach can digest. As fish grow, the stomach becomes longer, and their digestive system becomes more developed. However, the feeding rate relative to body weight decreases, whereas the absolute rate of food consumed increases (Wakil et al., 2014). The current feed compositions of tilapia also were showed the same phenomena.

\subsection{Food and feeding habit}

Among the 250 stomach content used to analyze the food composition in dry (March and April) and wet (July and August) months 49(19.6\%) were completely empty and 201 (80.4\%) observed full with phytoplankton, zooplankton, insects, mud and fish remain. This small amount of empty gut observed may be due to short time interval between capture and digestion loss or due to low digestibility of phytoplankton in small size fish.

This study showed that for tilapia from this reservoir, zooplankton as a group had the highest frequency of occurrence (Table 1). The major food item co nsumed by $O$. niloticus in Alwero dam were zooplankton (34\%) was followed by that of fish remain (27\%), phytoplankton (22\%), and the least consumed item were Insect parts $(9 \%)$ and $\mathrm{mud} / \mathrm{sand}(8 \%)$ (Table1). Several authors were reported differences on feeding habit of Nile tilapia. (Teame et al., 2016) was reported on lake Hashange, zooplankton was major food item consumed by Nile tilapia which in agreement with the current studies. In addition to zooplankton the highest contribution of fish was also reported in some rift valley lakes (Koka Reservoir (Engedaw etal., 2013) and Lake Langano (Temesgen, 2017) and Gilgel Gibe Reservoir (Wakjira, 2013). The occurrence of zooplankton in the diet of Nile tilapia was slightly highest in Alwero dam like some of the high land lakes reported by (Worie and Getahun, 2015) on Lake Hashange. (Filipos, 2013) reported on Lake Koka phytoplankton were the major food items for large size while Small sized fish $(<10 \mathrm{~cm})$ fed mainly on insects and zooplankton which was lined with current study.

Job and Udo (2002) and Northcott etal (1991) were reported that insects and crustaceans comprise a large portion of the diet of Oreochromis niloticus, Oreochromis niloticus have the ability of feeding on either small or bulky particles and can efficiently filter and utilize a broad range of particle sizes (Job and Nyong, 2004).The food items in the stomach content of Oreochromis niloticus indicates that zooplankton feed mainly on animal food substances comprising of insect pupae, insect larva, protozoa and detritus. This result was in agreement with Noble (1989), Gwahaba (1973) and Fagade and Olaniyan (1973) who reported that Oreochromis niloticus are obligate omnivores feeding, However, the less contribution of zooplankton was reported in other water bodies similar to results of current study.

Table 1: Frequency of occurrence of food items in the stomach of Oreochromis niloticus of Alwero dam

\begin{tabular}{lcc}
\hline \multirow{2}{*}{ Food items } & \multicolumn{2}{c}{ Frequency of occurrence } \\
\cline { 2 - 3 } & Number & Percentage (\%) \\
\hline Fish remains & 70 & 26.61 \\
Phytoplankton & 58 & 22.05 \\
Zooplankton & 90 & 34.22 \\
Mud/sand & 20 & 7.6 \\
Insect parts & 25 & 9.16 \\
Total & $\mathbf{2 6 3}$ & $\mathbf{1 0 0}$ \\
\hline
\end{tabular}

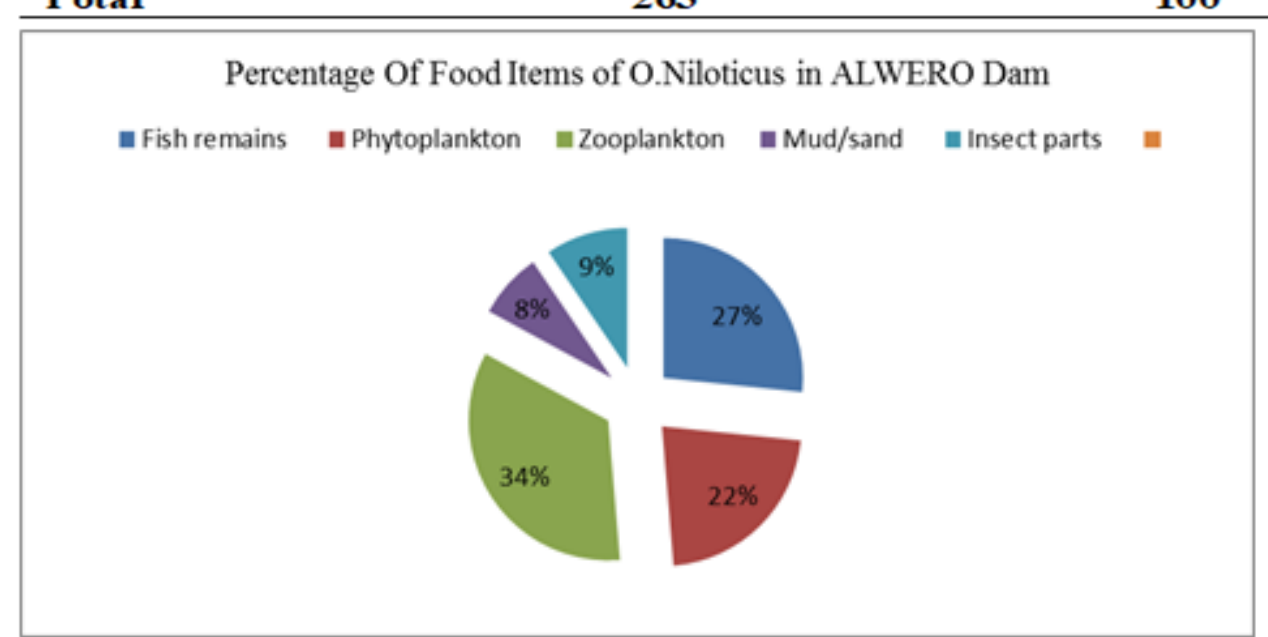

Fig. 2: Percentage of food item types in the stomach of Oreochromis niloticus of Alwero dam 


\subsection{Seasonal variation in the diet composition of Nile tilapia}

The result clearly demonstrates seasonal variation, during wet and dry season were $13.43 \%$ and $26.72 \%$ of the empty stomachs of 134 and 116 number of fish stomach examined respectively of food items contain.

The low proportion of phytoplankton during the wet season is associated with the high flooding from the catchment area, which can cause fluctuation in water level and increase turbidity (Njiru et al., 2004). Turbidity of water decreases the penetration of sunlight and affects the growth and abundance of phytoplankton (Paaijmans et al., 2008) are the most dominant phytoplankton in the diet of Nile tilapia reported during the dry season in most of the rift valley lakes, such as Lake Langeno (Temesgen, 2017), Lake Koka (Engedaw etal., 2013) and Lake Chamo (Teferi et al., 2000. This was maybe due to warm temperature made a lakes, ponds, and slow-moving streams enriched with nutrients like phosphorus or nitrogen are the most preferred habit for growth according to Wisconsin Department of Natural Resource (2004).

A lot of the studies indicated that phytoplankton is the most important food items consumed in dry season. For instance, the study made in Lake Koka showed that about $66.1 \%$ of the total volume of food items identified in the diet of Nile tilapia was phytoplankton followed by detritus 14.7\% (Engedaw et al., 2013). Similar findings were also reported in Lake Langeno (Temesgen, 2017) Lake Hayq (Worie and Getahun, 2015) [33], Lake Ziway (Negassa and Prabu, 2008), Lake Chamo (Teferi et al., 2000) and Omo River (Wakjira, 2016). The current studies also showed that phytoplankton was very important followed by zooplankton dry season in lined with those authors. However, in wet season the high contribution of both plant origin (macrophytes and mud /sand) and animal origin (zooplankton and aquatic insects) were reported in most of the water bodies (Engedaw et al. 2013; Negassa and Prabu, 2008; Teame et al., 2016; Temesgen, 2017; Wakjira, 2013; Worie and Getahun, 2015).

Many studies have indicated that the feeding habit of the tropical fishes is dependent on the resource accessibility in the environment, which was determined the choices and feeding preferences fish based on their trophic niches/or foraging areas (Ahrens et al. 2012; da Silva et al., 2014). Also the Nile tilapia in Alwero dam feed on different plant and animal origin and shifting their feeding ability depending on availability.

Table 2: seasonal feeding activity of Oreochromis niloticus

\begin{tabular}{rccccc}
\hline No & $\begin{array}{c}\text { Season of } \\
\text { year }\end{array}$ & Number & $\begin{array}{c}\text { number of Stomach } \\
\text { Examined. }\end{array}$ & $\begin{array}{c}\text { number of empty } \\
\text { Stomach }\end{array}$ & $\begin{array}{c}\text { \% of empty } \\
\text { stomach }\end{array}$ \\
\hline 1 & Dry season & March & 78 & 7 & 8.9 \\
& April & 56 & 11 & 19.64 \\
2 & Wet season & July & 62 & 17 & 27.41 \\
& August & 54 & 14 & 25.92 \\
\hline & & 250 & 49 & 19.6 \\
\hline
\end{tabular}

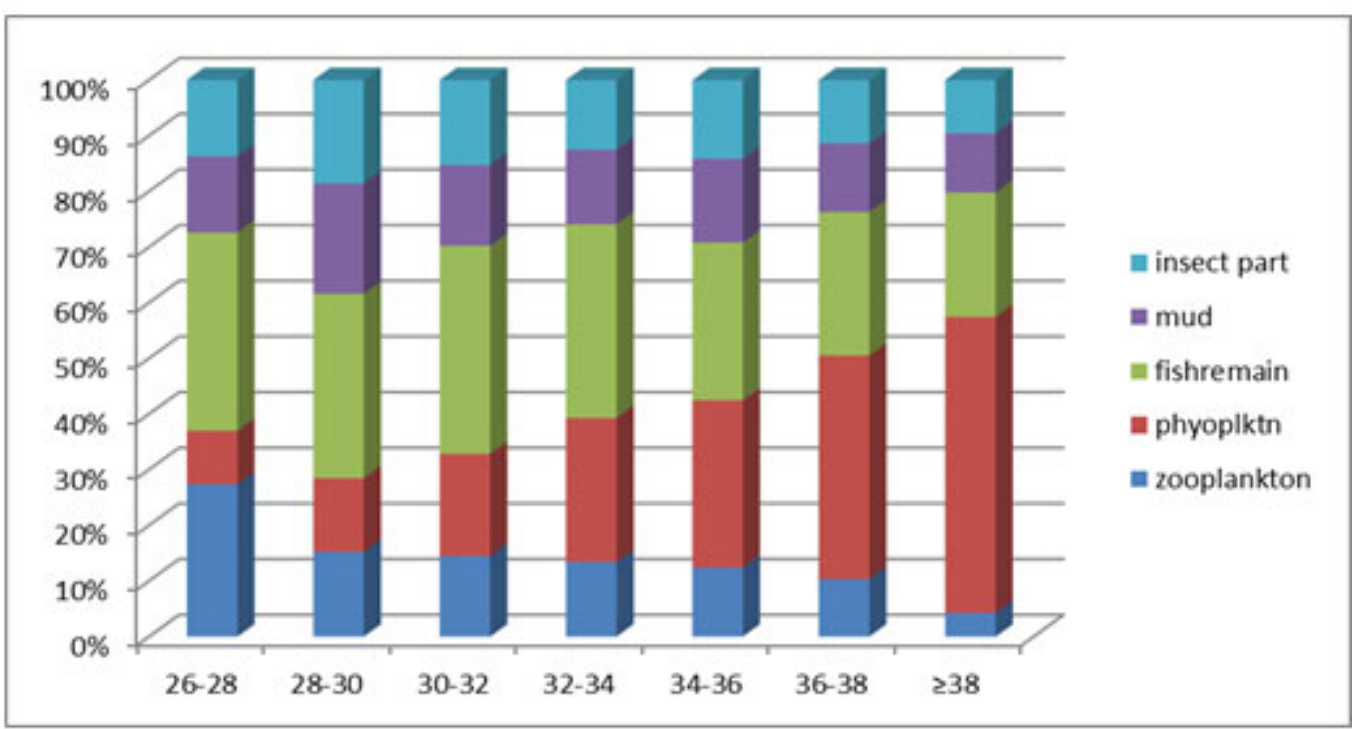

Figure 3: Frequency occurrence $(\% \mathrm{O})$ of different food items in relation to fish size of $\mathrm{O}$. Niloticus fish from Alwero dam

\subsection{Ontogenetic diet shift}

According to Otieno et al. (2014), fish was mainly feed on food items that could fit into their mouth, and what 
their stomach can digest. As fish grown, the stomach becomes longer and their digestive system becomes more developed. However, the feeding rate relative to body weight decreases, whereas the absolute rate of food consumption was increased (Wakil et al., 2014).

The ontogenetic dietary shift of O. niloticus in Lake Victoria highlights zooplankton were most Important food items for fish less than $5 \mathrm{~cm}$ TL and little importance for largest fish (Njir et al., 2004). In the present study fishes $<28 \mathrm{~cm}$ TL eaten on zooplankton and fish remain diet while as size increased from $28 \mathrm{~cm}$ TL to the $\geq 34 \mathrm{~cm}$ TL, they would shifted to phytoplankton. Teferi etal. (2000) was reported on the size based feeding study of O. niloticus in lake chamo, which showed highly dominance animal origin foods in the diet of fish with $<11.5 \mathrm{~cm}$ TL. For instance, zooplankton $(37.5 \%)$, insect $(35 \%)$ and nematodes $(13.5 \%)$ were the most frequently consumed food items by $<11.5 \mathrm{~cm}$ TL. Similarly, insects $(30 \%)$ and zooplankton $(25 \%)$ were the highly consumed food preys in Lake Koka by fish with $<10 \mathrm{~cm}$ TL (Engedaw etal., 2013), which in agreed with the current study.

According to Benavides et al. (1994), Nile tilapia change their feeding behavior from primarily omnivorous to herbivorous with the high-energy demands as they grow in size. The growing demand of energy may be cannot be met by feeding only on zooplankton and benthic invertebrates. Due to this they shift their feeding behavior from eating only zooplankton and benthic invertebrates to the generalist behavior. Additionally the bigger fish are more capable of digesting cell wall material, therefore can be less selective in their feeding pattern. The shift in feeding behavior shows a low degree of intraspecific competition for particular food among different length groups (Ayoade et al., 2000)

\subsection{Relationship of total weight (TW)-total length (TL)}

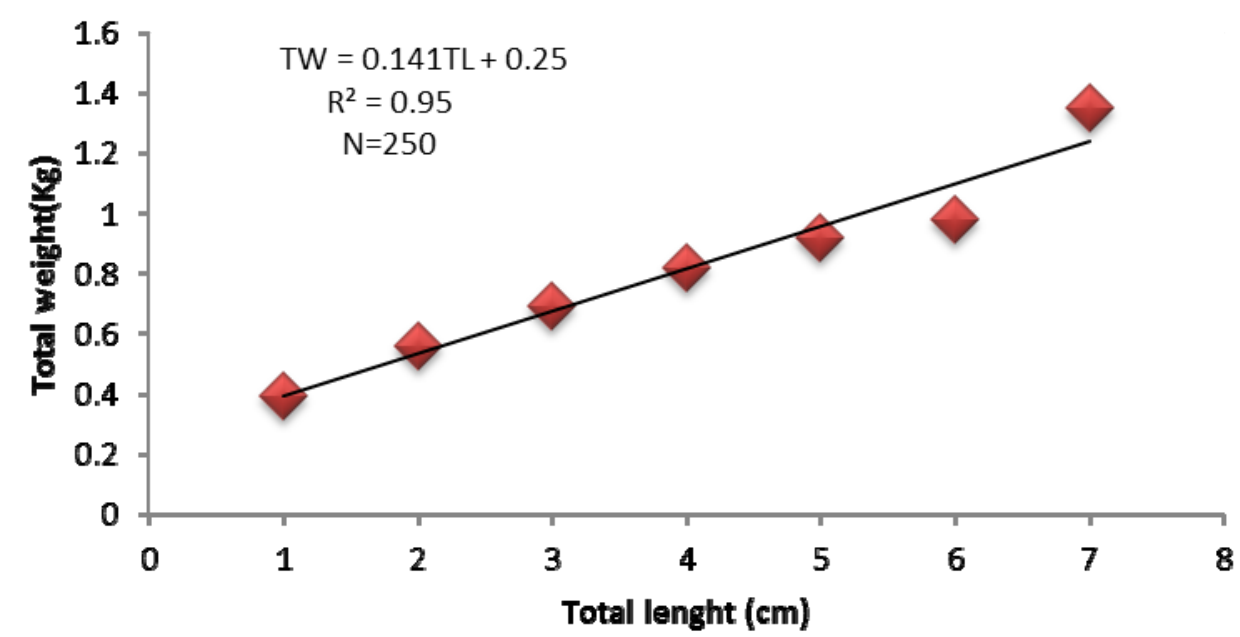

Figure 5: Total Length and Total weight relationship of O. Niloticus $\mathrm{TW}=0.14 \mathrm{TL}+0.025 \quad \mathrm{R}^{2}=0.96 \quad \mathrm{~N}=250$

The morphometric relation between total length (TL) and total weight (TW) of O. niloticus in Alwero dam was linear with equation $\mathrm{TW}=0.14 \mathrm{TL}+.025$ and highly significant at $(\mathrm{p} \geq 0.1)$ with $\mathrm{R}^{2}=0.95$ it indicates strong morphometric relationship. This linear relationship between TW and TL indicates either of the length measurement can be converted into the other, or can be estimated from the other. It has been observed that there was a significant difference between the total length and total weight of Oreochromis niloticus at $(\mathrm{P}<0.001)$, this means that as the weight of the fish increases or decreases, the total length also increases or decreases in size.

\section{Conclusion}

According to these results revealed that the, Oreochromis niloticus in Alwero dam was omnivorous fish fed on zooplankton, fish remain, phytoplankton, insect part and muds from major food to minor food respectively. They were selected food based on their size related to digesting and foraging ability. Also, they were shifted their food and feeding preferences based on seasonal changes. Morphometric relationships of total weight (TW) total length (TL) showed a linearity line which indicated fish length affected by weight and vice-versa

\section{REFERENCESA.}

Abebe Getahun (2007). An overview of the diversity and conservation status of the Ethiopian fresh water fish fauna. J. Afrotrop. Zool. Special issue, 21(2): pp 87-96Arhens B, Jennifer M, Michael B, Orger, Drewn, 
Robson, Alexander F et al. Brain-wide neuronal dynamics during motor adaptation in zebrafish, 2012, 471477.

Ayoade A, Fagade S, Adebisi A. Diet and dietary habits of the fish Schilbemystus (Siluriformes: Schilbeidae) in two artificial lakes in Southwestern Nigeria. International Journal of Tropical Biology. 2008; 56:1847-1855.

Benavides A, Cancino J, Ojeda F. (1994). Ontogenetic change in stomach dimensions \& microalgal digestibility in marine herbivore fish A. punctatus. Functional Ecology. 8:46-55

Bianco, P. G., and P. Turin. 2010. Record of two established populations of Nile tilapia, Oreochromis niloticus, in freshwaters of northern Italy. Journal of Applied Ichthyology 26:140-142.

C. D. Van der Lingen, A. Bertrand, A. Bode et al., "Trophic dynamics of small pelagic fish," in Climate Change and Small Pelagic Fish, D. Checkley, C. Roy, J. Alheit, and Y. Oozeki, Eds., chapter 8, p. 372, Cambridge University Press, 2008. View at Google Scholar

Demeke Admassu, Lemma Abera and Zenebe Tadesse (2015). The food and feeding habits of the African catfish, Clarias gariepinus (Burchell), Lake Babogaya, Ethiopia. Global J. of fisheries and aquaculture, 3(4), pp 211-220

Engdaw F, Dadebo E, Nagappan R. Morphometric relationships and feeding habits of Nile tilapia Oreochromis niloticus (L.) (Pisces: Cichlidae) from Lake Koka, Ethiopia. International Journal of Fisheries and. Aquatic Science. 2013; 2:65-71.

Engdaw F, Dadebo E, Nagappan R. Morphometric relationships and feeding habits of Nile tilapia Oreochromis niloticus (L.) (Pisces: Cichlidae) from Lake Koka, Ethiopia. International Journal of Fisheries and. Aquatic Science. 2013; 2:65-71.

FAO (Food and Agriculture Organization of the United Nations). 2018. Oreochromis niloticus (Linnaeus, 1758). Cultured Aquatic Species Information Programme, Fisheries and Aquaculture Department,FAO,Rome. Available: http://www.fao.org/fishery/culturedspecies/Oreochromis_niloticus/en. (January 2018).

Flipos Engdaw, Elias Dadebo and Raja Nagappan Morphometric Relationships and Feeding Habits of Nile Tilapia Oreochromis niloticus (L.) (Pisces: Cichlidae) From Lake Koka, Ethiopia Int. J. Fish. Aquat. Sci., 2(4): $65-71,2013$

Girma Tilahun and Ahlgren, (2010). Seasonal variations in phyto- plankton biomass and Primar productionin the Ethiopian Rift Valley lakes Ziway, Awassa and Chamo. Limnologica, 40:330-342.

M. Arun Kumar, G. Padmavati, and S. Venu (2015). Food and Feeding Dynamics of Stolephorus commersonnii (Lacepede, 1803) (Family: Engraulidae) from South Andaman

N. E. Abdel-Aziz and S. M. Gharib, "Food and feeding habits of round Sardinella (Sardinella aurita) in El-Mex Bay, Alexandra, Egypt," Egyptian Journal of Aquatic Research, vol. 33, pp. 202-221, 2007. View at Google Scholar

Negassa A, Prabu PC. Abundance, food habits and breeding season of exotic Tilapia zillii and native Oreochromis niloticus L. fish species in Lake Ziway, Ethiopia. Maejo International Journal of Science \& Technology. 2008; 2(2):345-360. 18.

Njiru M, Okeyo-Owuor JB, Muchiri M, Cowx IG. Shifts in the food of Nile tilapia, O. niloticus (L.) in Lake Victoria, Kenya. African Journal of Ecology. 2004; 42:163-170.

Otieno ON, Kitaka N, Njiru JM. Length-weight relationship, condition factor, length at first maturity and sex ratio of Nile tilapia, O. niloticus in Lake Naivasha, Kenya. International Journal of Fisheries \& Aquatic Studies. 2014; 2:67-72

Pauly, D. (1993). Linear regressions in fisheries research. Journal of the Fisheries Research Board of Canada, 30:409-434

S. Hajisamae, L. M. Chou, and S. Ibrahim, "Feeding habits and trophic relationships of fishes utilizing an impacted coastal habitat, Singapore," Hydrobiologia, vol. 520, no. 1-3, pp. 61-71, 2004. View at Publisher · View at Google Scholar · View at Scopus

Teame T, Natarajan P, Zelealem T. Analysis of Diet and Biochemical Composition of Nile Tilapia (O. niloticus) from Tekeze Reservoir and Lake Hashenge, Ethiopia. Journal of Fisheries Livestock Production. 2016; $4: 172$

Tefera G. The Composition and Nutritional Status of the Diet of O. niloticus L. (Pisces: cichlidae) in Lake Chamo, Ethiopia. Journal of Fish Biology. 1993; 42:65-874. 26.

Teferi Y, Admasu D, Mengistu S. The food and feeding habit of O. niloticus L. in Lake Chamo, Ethiopia. SINET: Ethiopian Journal of Science. 2000; 23:1-12.

Temesgen M. Stuatus and trends of fish and fisheries in Lake Langano, Ethiopia. PhD dissertation submitted Department of Zoological Sciences, Addis Ababa University, Ethiopia, 2017, 243

Wakil U, Haruna A, Mohammed G, Ndirmbita W, Yachilla B, Kumai M. Examinations of the stomach contents of two fish species (C. gariepinus and O. niloticus) in Lake Alau, North-Eastern Nigeria. Agriculture, Forestry \& Fishery. 2014; 3:405-409.

Wakjira M. Feeding Habits and Some Biological Aspects of Fish Species in Gilgel Gibe I Reservoir, Ethiopia. 
International Journal of Current Research. 2013; 5:4124- 4132

Wisconsin Department of Natural Resources Blue-green algae in Wisconsin waters frequently asked questions, Wisconsin, 2004, 10.

Worie W and Getahun Abebe (2015). The food and feeding ecology of Nile tilapia, O. niloticus, in Lake Hayq, Ethiopia. Journal of Fisheries \& Aquatic Studies; 2:176-185. 